\title{
Challenges in using anesthesia for open chest and aorta surgery in swine ${ }^{1)}$
}

\author{
MACIEJ M. KOWALIK, PIOTR SIONDALSKI*, MAGDALENA KOŁACZKOWSKA*, \\ WAC ŁAW ZAJAC ${ }^{* *}$, PAULINA PAŁCZYŃSKA***, EWELINA CACKOWSKA, \\ GRZEGORZ JABŁOŃSKI***, ANDRZEJ BORMAN***
}

\author{
Department of Cardiac Anesthesiology, Medical University of Gdańsk, ul. Dębinki 7, 80-211 Gdańsk, Poland \\ *Department of Cardiac and Vascular Surgery, Medical University of Gdańsk, ul. Dębinki 7, 80-211 Gdańsk, Poland \\ **Wetprom, Veterinary Clinic, Zwycięstwa 333, 75-001 Koszalin, Poland \\ ***Department of Animal and Human Physiology, Faculty of Biology, University of Gdańsk, \\ ul. Wita Stwosza 59, 80-308 Gdańsk, Poland
}

Kowalik M. M., Siondalski P., Kołaczkowska M., Zając W., Pałczyńska P., Cackowska E., Jabłoński G., Borman A.

\section{Challenges in using anesthesia for open chest and aorta surgery in swine}

Summary

Anesthesia for aorta surgery in pigs remains challenging due to the requirements for mechanical ventilation and the need for maintaining adequate homeostasis. We report an improved anesthesia protocol in an in vivo animal model to test a novel bacterial nanocellulose (BNC) within the 'Kardio-BNC' trial. Forty-four 6-month-old DanBred pigs comprising 6 males and 38 females (body weight ca. $82 \mathrm{~kg}$ ) underwent implantation of pericardium reconstructive patches $(n=8)$, thoracic aorta prostheses $(n=15)$, or both procedures $(n=17)$ to test the biocompatibility of the novel BNC. The primary endpoint was 90-day survival, and the secondary outcome was death for any reason before reaching the study endpoint. Univariate analysis and linear regression were used to identify variables associated with premature mortality. Of the 44 pigs that underwent surgery, $10(23 \%)$ were lost intra-operatively because of arrhythmia $(n=1)$, anesthesiological causes $(n=4)$, or surgical complications $(n=5)$. Modifications to tracheal intubation, tube fixation, temperature maintenance, and vascular catheterization increased the survival rate to $91 \%$ in the last quartile of the animals that underwent surgery. Of the 34 animals that survived surgery, $n=10(29 \%)$ were lost post-operatively because of hematoma $(n=2)$, pneumothorax $(n=1)$, or infection $(n=7)$. Infection was associated with the type of surgery (highest prevalence in animals undergoing the combined procedure; $p=0.02)$, azaperone dose $(p=0.03)$, intra-operative heart rate variability $(p=0.03)$, and crystalloid transfusion $(p=0.04)$. The anesthesiological strategies and modifications to surgery described here allowed safe open chest and aorta surgery in up to $91 \%$ of the procedures performed.

Keywords: swine anesthesia, bacterial nanocellulose, aorta prosthesis, epicardium reconstruction

Large animals, such as swine or sheep, are often used during the initial evaluation of the biocompatibility of new materials developed for use in human medicine particularly in vascular and cardiac surgery $(1,3,8-10$, $16,17,19)$. Without such studies, the development and clinical use of artificial and biological heart valve prostheses would not be possible, preventing the opportunity to successfully treat hundreds of thousands of patients with these devices $(1,9)$. The search for new materials suitable for use in reconstructive, vascular and cardiac surgery is continuing. A promising new material is bacterial nanocellulose $(\mathrm{BNC})(17,18)$.

The 'Kardio-BNC' study was funded by the Polish National Center for Research and Development (NCBiR - Narodowe Centrum Badań I Rozwoju) [grant ID 211238].
$\mathrm{BNC}$ is synthesized by genetically modified bacteria and is available in thin layers. These BNC membranes are considered suitable for replacing several human tissues, including skin, dura mater, epicardium, aortic and arterial wall, pleura, and even heart valve cusps $(6,13,15,18)$. Because humans and other mammals do not produce enzymes to metabolize cellulose, it is resistant to biodegradation (18). BNC is intensively studied by several research centers worldwide and has recently been licensed for use as artificial dura mater, in blood vessel prostheses, skin grafts or as wound dressing material (18). The high resistance of thin layers of BNC to mechanical forces makes it a promising material for use in artificial vascular - particularly arterial - prostheses and as a reconstructive material 
for layers of mucosa, such as the pericardium or pleura in humans $(6,13,14,18)$. However, before BNC can be used for these purposes, it requires testing in large animal models such as swine or sheep, which might present biological responses to the material in a similar manner as human responses. Such studies require complex infrastructure and logistics and adequate skills in thoracic and vascular surgery as well as appropriate general anesthesia and veterinary care $(5,8,12)$.

Anesthesia for use with open chest surgery in pigs (aorta surgery in particular) remains challenging due to the need for controlled mechanical ventilation, accurate blood pressure control, and homeostasis maintenance $(8,19)$. The duration of the operation, eventual blood loss, and fluid and body temperature changes can contribute to the development of life-threatening arrhythmias and homeostasis disturbances.

Here, we report an analysis of perioperative mortality in a series of large pigs used in a surgical animal model to test two types of BNC as thoracic aorta prostheses or epicardial patches. The anesthesia protocol developed based on this experience is presented in accordance with the 3 Rs policy, with hopes that it will be helpful to other teams working with large pigs and other large animals in adequate planning of experimental groups, reducing failures, and preventing unnecessary loss of the animals (12).

The objective of this analysis was identification of errors and shortcomings of the applied anesthesia protocol in an open chest and aorta surgery animal model in large pigs used to test surgical usefulness and biocompatibility of a novel BNC.

\section{Material and methods}

Animals. In total, 44 DanBred pigs underwent one of three types of open chest surgery within the 'Kardio-BNC' study: a preclinical animal study investigating the biocompatibility of BNC for use in aortic prostheses and pericardium reconstructive patches. The different surgeries were performed consecutively according to increasing levels of surgical complexity as follows: pericardial patches, thoracic aorta prostheses, and a combination of both procedures; the aim was to accumulate experience during the less complex procedures and to prevent unnecessary animal deaths. The

Tab. 1. Baseline characteristics of the experimental animals, housing, and husbandry conditions

\begin{tabular}{|c|c|}
\hline Characteristics & Description \\
\hline \multicolumn{2}{|r|}{ Experimental animals } \\
\hline Breed & DanBred swine, F1-line; hybrid of the Danish Great White and Yorkshire breeds \\
\hline Age $[$ mean \pm SD] & $5.8 \pm 0.5$ months \\
\hline Weight [mean \pm SD] & $82 \pm 13 \mathrm{~kg}$ \\
\hline Sex & Males $n=6(13.6 \%)$, females $n=38(86.4 \%)$ \\
\hline Immune status & $\begin{array}{l}\text { Vaccinated against PCV2 (porcine circovirus 2) with Ingelvac CircoFlex and against mycoplasma with Ingelvac } \\
\text { MycoFlex (Boehringer Ingelheim Vetmedica, Ingelheim, Germany) }\end{array}$ \\
\hline Microbiological status & $\begin{array}{l}\text { Specific pathogen free: PRRS (porcine reproductive and respiratory syndrome virus), MHS (malignant hyperthermia- } \\
\text { susceptible), APP (Actinobacillus pleuropneumoniae), HPS (Haemophilus parasuis - Glasser's disease), and PAR } \\
\text { (porcine atrophic rhinitis), MHP (Mycoplasma hyopneumoniae) }\end{array}$ \\
\hline Antibiotic prophylaxis & Ceftiofur (Naxcel) $2.5 \mathrm{mg} / \mathrm{kg}$ im (Zoetis Belgium SA, Louvain-la-Neuve, Belgium) at 3.5 months of age \\
\hline Interventions prior to surgery & $\begin{array}{l}\text { Isolation from herd } 7 \text { to } 10 \text { days before surgery to avoid infection. } \\
\text { Tulathromycin (Draxxin) } 1 \mathrm{~mL} / 40 \mathrm{~kg} \text { im (Zoetis Belgium SA, Louvain-la-Neuve, Belgium) } 2 \text { to } 7 \text { days before surgery }\end{array}$ \\
\hline Method of transport & Transported in a closed car adapted for animal transport to the $\mathrm{OR}$ facility on the day of the operation \\
\hline \multicolumn{2}{|r|}{ Husbandry } \\
\hline $\begin{array}{l}\text { Measures to protect microbiological } \\
\text { status before and after operation }\end{array}$ & $\begin{array}{l}\text { Closed system - pigs grew up in a farm with increased biosecurity measures, restricted access, obligatory protective } \\
\text { clothes, and entry disinfecting mats }\end{array}$ \\
\hline Housing equipment, animals in pens & Hall with 10 full-grid breeding pens $(5 \times 8 \mathrm{~m})$ and two selection pens $(2 \times 4 \mathrm{~m})$ with automated feeders \\
\hline Animals in pen & $\begin{array}{l}\text { Experimental animals were kept separate from the herd in one breeding pen (maximum } 16 \text { animals per pen); during } \\
\text { the recovery period after surgery (ca. } 7 \text { days), pigs were kept in selection pens (maximum 2-3 animals per pen) }\end{array}$ \\
\hline Bedding & Non-litter \\
\hline Environmental temperature & Regulated at $21 \pm 1.0^{\circ} \mathrm{C}$ \\
\hline Relative humidity & Regulated $55 \% \pm 10 \%$ \\
\hline Lighting & Natural and artificial \\
\hline Air changes per hour & Min. $30 \%$ of hall volume/hour; adjusted automatically in accordance to temperature and humidity \\
\hline \multicolumn{2}{|r|}{ Feeding } \\
\hline Feed & $\begin{array}{l}3 \text { to } 4 \text { months - 'Starter' forage (Wipasz, Wadąg, Poland); } \\
4 \text { to } 5 \text { months - 'Grower' forage (Wipasz, Wadąg, Poland); } \\
5 \text { months to endpoint - 'Finisher' forage (Wipasz, Wadąg, Poland); } \\
\text { supplements Polfamix B-compositum (Polfa, Kutno, Poland) were added to each forage }\end{array}$ \\
\hline Water & Main water, untreated, supplied through nipple bottles ad libitum \\
\hline
\end{tabular}


operations were performed between 24 August 2015 and 27 September 2016. Assignment of animals to the surgical groups was random. Detailed characteristics of the experimental animals, housing, and husbandry conditions are provided in Table 1.

Ethical statement. The study protocol was approved by the Local Ethics Commission for Research on Animals in Gdańsk, Poland (40/2013; 10/07/2013). The study was performed in accordance with ISO 5840, the ARRIVE guidelines, and the EU Directive 2010/63/EU regarding animal experiments $(2,5,11,12)$.

Setting. The operations were performed in the operating theater of the Experimental Animal Laboratory at the Department of Animal and Human Physiology, Faculty of Biology at the University of Gdańsk, Poland. The OR is airconditioned. There is also a large animal preparation room containing single boxes with non-littered full-grid covered with a rubber mat. These boxes were supplied with running water drinkers and feeders.

Anesthesia. Two or three operations were performed on each operation day. Three selected animals were brought from the breeding farm and placed in single boxes within the preparation room. Before operation, a premedication consisting of 1) $6 \mathrm{mg} / \mathrm{kg}$ azaperone (STRESNIL 40, Janssen Pharmaceutica N.V., Beerse, Belgium), 2) $2 \mathrm{mg} / \mathrm{kg}$ xylazine (SEDAZIN $^{\circledR}$, Biovet Puławy Sp. z o.o., Puławy, Poland), and 3) $15 \mathrm{mg} / \mathrm{kg}$ ketamine (BIOKETAN ${ }^{\circledR}$, Vetoquinol Biowet Sp. z o.o., Gorzów Wielkopolski, Poland) was given intramuscularly $(\mathrm{im})$. When the animal lost consciousness, it was transported, washed clean with warm water and antiseptic soap, dried, and placed on its back on the operation table. The position was stabilized with tape fixed to the animal's legs and the table. Noninvasive monitoring (ECG and pulsioximetry) was started and recorded every 10 minutes on standardized anesthesia protocol sheets. A 20-G Venflon cannula was placed in the left auricular vein, and an infusion of warmed Ringer solution was started. After skin disinfection through a $5-8 \mathrm{~cm}$ incision ca. $3 \mathrm{~cm}$ lateral and parallel to the trachea, the left internal cervical artery and jugular vein were visualized by surgical preparation and cannulated with single-lumen $16 \mathrm{G}$ or $14 \mathrm{G}$ central venous cannulas (Certofix Mono S 315 and Certofix Mono S 415, B. Braun Melsungen AG, Melsungen, Germany), respectively. Continuous invasive arterial and venous blood pressure monitoring was conducted on the respective lines. Tracheal intubation was facilitated with bougie introducer and a tracheal tube, size No. 9.0, was inserted to a depth of $30 \mathrm{~cm}$. The tube was fixed using a cotton band. Mechanical ventilation (18-20 breaths $/ \mathrm{min}$ of $6-7 \mathrm{~mL} / \mathrm{kg}$ tidal volume) was started using a Siemens Servo Ventilator 900C, and $50 \mathrm{mg}$ rocuronium (Esmeron $\AA$, Organon N.V., Oss, Netherlands) was given $i v$ in one bolus and continued at a dose of $1-2 \mathrm{mg} / \mathrm{kg} /$ hour in $i v$ infusions together with fentanyl (Fentanyl WZF, Warszawskie Zakłady Farmaceutyczne Polfa SA, Warszawa, Poland) at a dose of 5-15 $\mu \mathrm{g} / \mathrm{kg} /$ hour and propofol (Propofol-Lipuro 2\%, B. Braun Melsungen AG, Melsungen, Germany) at 2.5-7.5 mg/kg/hour. If atrial fibrillation occurred during surgery, amiodarone was given at a dose of $150 \mathrm{mg} i v$ and repeated in 50-mg doses until cardioversion into sinus rhythm was achieved. The infusion of rocuronium was discontinued after chest closure, and fentanyl and propofol were discontinued at skin closure. The arterial and central venous lines were removed upon surgical closure of the holes in the vessel walls. Upon the recovery of self-breathing, a dose of $200 \mathrm{mg}$ of sugammedex (Bridion $^{\circledR}$, N.V. Organon, Oss, Netherlands) was given $i v$. The tracheal tube was removed after stable respiration with tidal volumes of ca. $10 \mathrm{~mL} / \mathrm{kg}$ was recovered and hemoglobin oxygen saturation remained stably over $95 \%$.

Surgery. Three types of BNC implantation were performed: epicardial patch, thoracic aorta prosthesis, and a combination of both. Through left thoracotomy in the $5^{\text {th }}$ intercostal space, the pleura was opened. In the pericardium, a hole of ca. $6 \mathrm{~cm}$ was cut, and the tissue was replaced with a BNC patch. For aortic prosthesis implantation, a length of ca. $10 \mathrm{~cm}$ of descending aorta was prepared. After a dose of 10,000 IU of heparin was given $i v$, the activated clotting time was measured, a 3/8-inch aorto-aortic shunt was placed, and the aorta was clamped with two cross clamps. The aorto-aortic BNC prosthesis was sewn, air was removed from the clamped part, and the flow was restored. The heparin treatment was reversed using protamine sulfate. In selected cases, after risk evaluation by the team consisting of the veterinarian, the anesthesiologist and the surgeon, a combined operation of both above-described procedures was performed.

Post-operative analgesia and treatment. After removal of the tracheal tube and before transport to the pen, the swine received $50 \mathrm{mg} / \mathrm{kg}$ metamizol im (BIOVETALGIN 0.5/1 mL, Biowet Drwalew SA, Drwalew, Poland) for postoperative analgesia. The animals spent the first post-operative hours in single boxes in the preparation room supervised by a qualified veterinary technician and the veterinarian. Additional doses of metamizol were repeated every 6-8 hours during the first 24 post-operative hours. Continuation of the post-operative analgesia on the second and third postoperative days was maintained through meloxicam $0.4 \mathrm{mg} /$ kg im (Contacera, Pfizer Ltd., Sandwich, Kent, UK) given in two doses per day.

At the end of the operating day the operated animals were transported back to the farm and placed in separate pens. Water and forage supplies were given as described above. Post-operative care was delivered by trained technicians and the veterinarian. During the recovery period, the animals were assessed for their behavior, drink and food intake, breath rate, and pain symptoms. If the animals presented symptoms of pain (i.e., groaning, limited movements, anorexia, wavering chest movements on breathing), additional doses of analgesics were applied. During the first post-operative week, the animals were assessed daily for symptoms of pain, their ability to move, food and water intake, and body temperature. Post-operative wound site infection prophylaxis was maintained for seven days by application of penicillin $\mathrm{G}$ with streptomycin (Pen-Strep $200+250 \mathrm{mg}$, Scan-Vet, Gniezno, Poland) at a dose of $0.1 \mathrm{~mL} / \mathrm{kg}$ im given once a day and wound disinfection with an alcoholic iodine solution. Additionally, the animals received injections of Calfoset at $0.1 \mathrm{~mL} / \mathrm{kg} \mathrm{im}$ (Krka, Nove Mesto, Slovenia) for three days to correct calcium and phosphorus homeostasis. 
Euthanasia and humane endpoints. After at least ninety days of follow-up after BNC prostheses implantation, the animals were euthanized in accordance with European Union Directive 2010/63/EU using an anesthetic overdose of $1 \mathrm{mg} / \mathrm{kg}$ of pentobarbital intravenously (iv) (Morbital ${ }^{\circledR}$, Biowet-Puławy Sp. z o.o., Puławy, Poland) (5). Tissue blocks containing the BNC implants were cut from the animal post-mortem and submitted for pathomorphological examination. The defined humane endpoints that would finish the experiment before the set time-point were as follows: 1) lethal cardiac arrhythmia, 2) inability to recover from anesthesia with effective breathing, or 3) inability to regularly intake water or forage for longer than 24 hours or three days, respectively. In such cases, preemptive euthanasia was performed.

Outcome measures. The primary endpoint of the study was survival after 90 days of BNC implantation. The animals were examined for implant tolerance, which will be reported elsewhere. All animals who died before the primary endpoint were examined post-mortem for the cause of death and the biocompatibility of the BNC prostheses. For the purpose of the current analysis, we defined death and its causes before reaching the primary outcome as secondary outcome measures. Causes of death were estimated by consensus of the surgeons, the anesthesiologist, and the veterinarian. Based on a critical review of the causes of death, we defined two categories of intra-operative causes: anesthesiological and surgical. Additionally, three causes of premature death were identified upon autopsy in animals that survived the operation but did not reach the primary endpoint: infection, in the presence of abscesses or phlegmon or pneumonia; pneumothorax, when a collapsed lung occurred and free air was found in the pleural cavities; and hematoma.

In addition to identifying the causes of death, a risk factor analysis of selected variables was performed for the animals that survived the operation but died of infection. Sex was not considered a prediction variable for post-operative complications. The following variables were tested for association with deadly infection: body weight, type and doses of premedication, doses of anesthesia drugs, intra-operative blood loss and crystalloid transfusion, type and duration of surgery, and intra-operative physiological parameters: systolic arterial blood pressure variance (SABPV), sinus rhythm heart rate variance (SRHRV) at selected time points, the occurrence of atrial fibrillation (AF) and ventricle fibrillation (VF), and superficial temperature. Additionally, white blood cells (WBCs) measured from blood samples obtained before the operation but after placement of the central venous catheter and after the operation but before removal of the venous catheter, as well as the difference between these values, were analyzed for association with infection-complicated post-operative course. The efficacy of the implemented corrections to the anesthesiological and surgical procedures was measured by comparing premature mortality rates and their causes between consecutive quartiles of the operated animal series.

Sample size and statistical methods. Using the Kelsey formula for unmatched case-control studies and assuming $80 \%$ power, a $95 \%$ two-sided confidence level, and a case: control ratio of 0.6 to define biological incompatibility of the BNC implants, the number of cases required for each surgical category was defined as $n=8(n=24$ total). The study was continued until reaching the calculated sample size alive at the set primary endpoint. Associations with secondary outcomes were identified by comparing the means between groups of normally distributed continuous data using the two-tailed Student's t-test, and the results are reported as the means and standard deviations (SDs). Nonnormally distributed data and categorical variables were compared using the Mann-Whitney $U$ test and are reported as medians and 25-to-75 inter-quartile range (IQR). Data distribution was tested using the Bartlett test. Differences in proportions were compared using the Mantel-Henszel (MH) chi-square test or Fisher's exact (FE) test when one of the compared groups was less numerous than 5 and are reported as odds ratios and 95\% confidence interval (CI). The results with $p$-values $\leq 0.05$ were considered significant.

\section{Results and discussion}

Of the operated series of $n=44$ pigs, $n=20$ were lost before the set study endpoint $-\mathrm{n}=10(23 \%)$ during operation and $n=10$ (29\% of the 34 which survived the operation) after surgery. Of the 34 animals which completed surgery, $\mathrm{n}=3$ were operated without aortic shunt. The case flow is presented in Figure 1. The causes of intra-operative and post-operative death were analyzed separately.

Intra-operative causes of death. In the 10 individuals lost intra-operatively, three groups of causes of

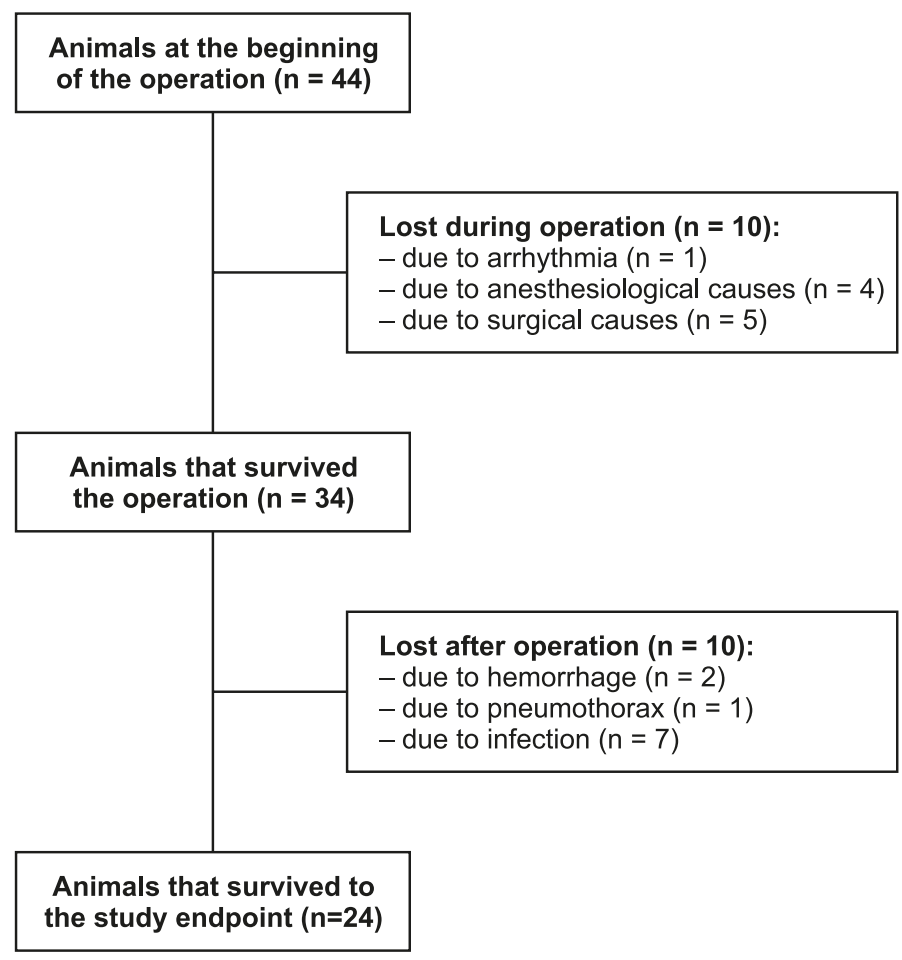

Fig. 1. The case flow diagram of the 'Kardio-BNC' animal study with causes of premature loss from the study

Explanations: Proportions of intra-operative death causes are calculated based on all animals in which the operation was started $(n=44)$. Proportions of post-operative death causes are calculated based on animals that survived the operation $(n=34)$ 
death were identified: due to anesthesiological procedures $(n=4)$, due to surgery $(n=5)$, and due to lethal arrhythmia $(n=1)$. The fifth-operated animal was lost at the end of uneventful surgery when unexpected VF occurred during skin closure. After a critical review of the possible causes, hypothermia was considered the causative reason. The main cause for loss due to anesthesiological reasons was a problem with ensuring appropriate ventilation. In one case (the third animal in the series), the animal was lost because of an inability to intubate the trachea after muscle relaxant administration. In two other animals, the tube flipped off the trachea upon turning the animal from its back on the site for surgery; before re-intubation, hypoxemia developed, and the cases were lost. The fourth individual, which was lost because of an anesthesiological mistake, passed successfully through the operation; however, on recovering from anesthesia, despite a successful self-breathing attempt through the tracheal tube, pharynx and neck edema developed after extubation and the animal died of suffocation.

The animals were subjected to three types of surgery. Beginning from the least complex epicardial patches, through thoracic aorta prostheses, to the most complex surgery, a combination of both procedures. Five pigs were lost due to causes that were qualified as "surgical reasons" (Fig. 1). Two of these died because of blood loss and one because of inappropriate positioning of the aortic shunt cannula in the carotid artery, which was suspected to have caused brain injury, resulting in a failed recovery from anesthesia after finishing surgery. Two animals were lost because of lethal, irreversible VF, which occurred during a transesophageal echocardiographically guided attempt to perforate the native aortic valve of the pigs.

With advancing experience in the use of the anesthesiological and surgical procedures, the success rate of the finished operations increased from $73 \%$ in the first quartile (the first $25 \%$ of the operated series) to $91 \%$ in the last quartile (Fig. 2). The worst results were obtained in the second quartile (success rate, $64 \%$ ), when more complex surgical procedures were performed on the aorta and a model involving the implantation of an artificial aortic valve was tested. To ensure that the artificial valve worked, an attempt was

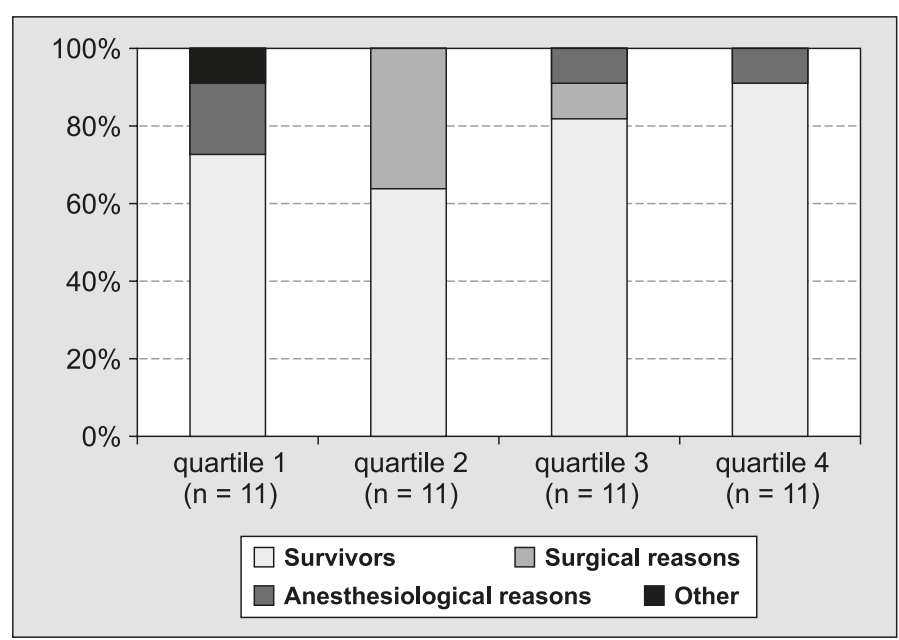

Fig. 2. Survival rates for the operation in consecutive quartiles (anesthesia and surgical "learning curve") in the KardioBNC trial

Explanations: Quartiles - consecutive $25 \%$ of the operated case series - each quartile contains $n=11$ animals. Other - arrhythmia

made to perforate the native valve; however, the pigs appeared to be critically sensitive to manipulations on the aortic valve and responded in both cases, despite pretreatment with amiodarone, with irreversible lethal VF to endovascular stimuli to the aortic valve. After these two failures, we refrained from further attempts to test the aortic valve prosthesis in this in vivo model on a beating heart, restricting the study to simple aortic prostheses and epicardial reconstructive patches.

Several measures were introduced into the perioperative protocol as new reasons for fatal surgery were identified (Tab. 2). These modifications resulted in an increase of the surgical success rate from $73 \%$ in the first quartile to $91 \%$ in the fourth quartile.

Post-operative causes of death. Of the 34 pigs in which different BNC prostheses were successfully implanted, $\mathrm{n}=10(29 \%)$ died before the primary study endpoint of a 90-day follow-up (Fig. 1). All prematurely lost animals were examined post-mortem for the main causes of death. Three reasons were identified: pneumothorax, hematoma, and infection. Pneumothorax probably occurred due to unrecognized intra-operative lung injury. Hematomas were found in two cases: in one animal, a large hematoma in the pleura and a suspected hemorrhage from the aorta were

Tab. 2. Modifications increasing safety introduced to the Kardio-BNC study protocol

\begin{tabular}{|c|c|c|}
\hline Issue & Death cause & Measures/modifications \\
\hline Difficult intubation & asphyxia, subcutaneous emphysema & $\begin{array}{l}\text { Intubation performed after premedication, on self-breathing, with the snout fixed with } \\
\text { tape to the frame of the table and the jaw elevated using another tape by an assistant }\end{array}$ \\
\hline Tracheal tube displacement & asphyxia & Tube fixed with cotton tape, which was put around the snout, across and behind the ears \\
\hline Intra-operative hypothermia & ventricular fibrillation & $\begin{array}{l}\text { Warming of fluids to } 40^{\circ} \mathrm{C} \text { before transfusion. } \\
\text { Wrapping with lignin and stretching foil over the lower part of the body }\end{array}$ \\
\hline Jugular vein cannulation & cervical hematoma, asphyxia & $\begin{array}{l}\text { Surgical opening after premedication, on self-breathing. } \\
\text { Surgical closure of the access point before extubation }\end{array}$ \\
\hline Carotid artery cannulation & cervical hematoma, asphyxia & $\begin{array}{l}\text { Surgical opening after premedication upon self-breathing. } \\
\text { Surgical closure of the access point before extubation }\end{array}$ \\
\hline
\end{tabular}


found; in the second, a large hematoma on the neck, compressing the trachea, with hemorrhage from the cannulated carotid artery occurred in the $34^{\text {th }}$ animal of the series. Small hematomas on the neck had been observed occasionally before this event but did not influence the post-operative course. After this complication, surgical closure of the catheter access points on the cervical vessels at the end of the operation was introduced instead of simple removal with manual compression of the access site. After this modification, no further neck hematomas were observed.

The most frequent cause of premature death after successful operation was infection $(\mathrm{n}=7 ; 21 \%)$ (Fig. 1). In four animals, abscesses around sutures or phlegmon in the pleura were found, indicating direct infection of the wound. Another two animals died of pneumonia, and an additional animal, which presented with foamy exudates in the pericardium during surgery, died 35 days after operation with hemorrhagic fluid in the pericardium (hemorrhagic pericarditis). One of the two animals with pneumonia died on the second day after operation, presenting with symptoms of respiratory failure before death. All other individuals with infection died between the $5^{\text {th }}$ and $7^{\text {th }}$ weeks after operation and presented with aggravated symptoms of infection, which remained resistant to introduced empirical antibiotic therapy using ceftiofur, several days before death. Using a univariate analysis, we identified four risk factors associated with lethal infection: type of surgery, azaperone dose, crystalloid transfusion volume, and SRHRV (Tab. 3). From this analysis the first three animals, which were operated without aortic shunt, were excluded to keep the group as homogeneous as possible. In a correlation analysis of these four variables, only azaperone dose was correlated with quartiles and type of surgery (respectively A and KW, $p<0.0000$ ). This finding is explained by the fact that higher doses were given to swine who were operated on for combined procedures in later quartiles. Finally, six of thirteen $(46 \%)$ swine who were operated on for combined procedures were lost to follow-up because of premature death from infection. According to a linear regression analysis, SHRV was not related $\left(\mathrm{R}^{2}<0.01\right)$ with any of the following perioperative variables that are attributable to infection: highest body temperature, body temperature variability, pre- and post-operative $\mathrm{WBC}$, and $\mathrm{WBC}$ change.

Discussion. To investigate the biocompatibility of a newly developed Polish variant of BNC (Bowil Biotech Sp. z o.o., Władysławowo, Poland), the 'Kardio-BNC' project team implanted BNC prosthe- ses into large (ca. $80 \mathrm{~kg}$ body weight) swine. Such animal models are often used during the initial steps of the development of new materials intended for use in human medicine $(1,3,9,10,16,19)$. The DanBred breed was chosen because of its reported resistance to stress and infection (source: DanBred International. DanBred Breeding Programme, http://www.danbredinternational.dk/sites/default/files/english/Teknik brochure_UK_HIGH_2009.pdf, accessed 4 April 2017) (7). However, despite the qualifications and experience of the team regarding the veterinary care of swine and human open chest and aorta surgery, some perioperative deaths during the initial stages of the project were attributed to important differences between animal and human anesthesia and surgery (8). A critical review of all fatal cases enabled the identification and elimination of deaths from these causes. This approach included measures performed by the anesthesiologist (maintaining stable body temperature, ensuring secure and effective trachea intubation, the prevention of tracheal tube dislodgement, and the secure placement and removal of vascular accesses) and by the surgeon (the 
prevention of bleeding, the use of appropriate shunt cannulas, and the control of sterilization procedures). The mandible is cone shaped in DanBred swine and offers no resistance to the cotton tapes used for tracheal tube fixation. After the loss of an animal because of tracheal tube displacement during positioning for surgery with taping of the tube to the mandible and the snout, we changed the method of tube fixation, leading the tape around the neck and behind the ears. Under this method, no further tube displacements occurred.

Open chest surgery (aorta surgery in particular) is associated with considerable compromise of the circulation. Despite the applied shunt, timely clamping of the thoracic aorta caused an increase of the afterload, as reflected by increased arterial pressure. However, release of the clamps was followed by timely arterial hypotonia. Hence, the combined procedures provided a reasonable injury to the animal, required greater crystalloid transfusion, and when the operation was associated with additional complications (i.e., bleeding or arrhythmia), this injury overcame the animals' ability to compensate. Finally, the possibilities for intensive therapy in animals, unlike in humans, are very limited. Therefore, continuous risk evaluation during the operation is reasonable and should be performed by a team comprising a veterinarian, an anesthesiologist, and a surgeon.

Another important difference between animal and human surgery, which caused the loss of another few cases, was related to the handling of post-operative bleeding. Unlike in humans after such operations, the pigs had no drains emplaced. Such drains could not be handled as they are in humans and would have posed a possible access site of infection, ascending along the drains. Hence, if post-operative bleeding occurred, hematoma could therefore lead to death, due to the lack of means to manage it, or if limited, could be converted in some cases into phlegmon or abscess.

Untreatable infection was a feared cause of premature death in the 'Kardio-BNC' study. Surprisingly, infection occurred relatively late (between the $5^{\text {th }}$ and $7^{\text {th }}$ post-operative week) in the majority of cases and was responsible for $70 \%$ of all premature deaths in animals in which the operation was successfully completed. Because the interpretation of microbiological cultures that are obtained post-mortem during autopsy is questionable, we did not identify the causative agents.

Because the mortality resulting from infection frequently occurred due to a coexisting pulmonary infection and was related to the type of surgery, we consider the surgical technique used to access the thoracic aorta as the causative reason for this complication. No variables associated with the animals' health status before operation were correlated with post-operative infection. In animals operated on for descending thoracic aorta prostheses, access to the aorta was obtained through left thoracotomy. The incision was kept as small as possible; however, to visualize the aorta, the lower lobe of the lung had to be collapsed and moved away using an S-shaped flat hook throughout the procedure. In combined procedures, where a pericardial patch was additionally implanted, the time of lung collapse was longest. Despite the performance of lung-recruiting maneuvers before closure of the pleura, these animals were particularly prone to later post-operative infections. Of the four intra-operative variables associated with infection, only azaperone dose was correlated with the type of surgery. Azaperone has not been reported to have an immunotoxic effect, but it causes salivation (4). Therefore, we hypothesize that increased secretion is possible also in the lower airways at higher doses of azaperone. In combination with prolonged lung collapse in the complex surgical procedures this might have predisposed animals to post-operative lung infection. However, this should be verified in further studies. The correlation with a higher transfusion of crystalloids was not related to intra-operative blood loss, and heart rate variability is considered unlikely to be an early sign of infection in the absence of any correlation with other symptoms and parameters of inflammation, such as body temperature and WBC.

The lack of information on the microbiota of the experimental animals might be considered as a shortcoming of the 'Kardio-BNC' study, as it hypothetically may influence the immunological response to $\mathrm{BNC}$, but when the study was designed in 2012 the demand for microbiota cultures in experimental animal studies addressing inflammatory diseases was not so explicit (2).

This critical case-by-case analysis of the premature loss of experimental animals allowed for a significant reduction of mortality in the 'Kardio-BNC' case series. We hope that this contribution will help other researchers refine their protocols and reduce experimental animal loss in accordance with the 3 Rs policy $(2,12)$.

In conclusion, modifications continuously introduced into the anesthesia protocol resulted in an improved survival rate during and after surgery despite the increasing complexity of the surgery. Differences between animal and human open chest surgery were considered responsible for unavoidable post-operative mortality both acutely and long-term after surgery, which was attributed to bleeding, pneumothorax and infection. Late post-operative infection was the primary cause of post-operative mortality.

\section{References}

1. Andersen H. R., Knudsen L. L., Hasenkam J. M.: Transluminal implantation of artificial heart valves. Description of a new expandable aortic valve and initial results with implantation by catheter technique in closed chest pigs. Eur. Heart J. 1992, 13, 704-708.

2. Bomzon A.: You and your research report: implementing the ARRIVE reporting guideline. Lab. Anim. 2017, 51, 121-123, doi: 10.1177/0023677216679442. 3.Brzeziński M., Bury K., Dąbrowski L., Holak P., Sejda A., Pawlak M., Jagielak D., Adamiak Z., Rogowski J.: The new 3D printed left atrial appendage closure with a novel holdfast device: a pre-clinical feasibility animal study. PLoS ONE 2016, 11, e0154559, doi: 10.1371/journal.pone.0154559. 
4. Committee for veterinary medicinal products. Azaperone - summary report. 1997. EMEA/MRL/300/97-Final.

5. Directive 2010/63/EU of the European Parliament and of the council of 22 September 2010 on the protection of animals used for scientific purposes. Offic. J. Eur. Union 2010, 276, 33-79.

6. Dtuga A., Kaczmarek H.: Characterisation of composites of bacterial cellulose and poly(vinyl alcohol) obtained by different methods. Fibres and Textiles in Eastern Europe 2014, 108, 69-74.

7. Fabrega E., Manteca X., Font J., Gispert M., Carrion D., Velarde A., Ruizde-la-Torre J. L., Diestre A.: Effects of halothane gene and pre-slaughter treatment on meat quality and welfare from two pig crosses. Meat Sci. 2002, 62, 463-472, doi: 10.1016/s0309-1740(02)00040-2.

8. Gallegos R. P., Nockel P. J., Rivard A. L., Bianco R. W.: The current state of in vivo pre-clinical animal models for heart valve evaluation. J. Heart Valve Dis. 2005, 14, 423-432.

9. Harvey L., Bianco R., Lahti M., Carney J., Zhang L., Robinson N.: CarpentierEdwards aortic pericardial bioprosthetic valve as a valid control in preclinical in vivo ovine studies. Eur. J. Pharmacol. 2015, 759, 192-199, doi: 10.1016/ j.ejphar.2015.03.033.

10. Iqbal J., Chamberlain J., Francis S. E., Gunn J.: Role of animal models in coronary stenting. Ann. Biomed. Eng. 2016, 44, 453-465, doi: 10.1007/ s10439-015-1414-4.

11. ISO 5840:2015 Cardiovascular implants - cardiac valve prostheses.

12. Kilkenny C., Browne W. J., Cuthill I. C., Emerson M., Altman D. G.: Improving bioscience research reporting: the ARRIVE guidelines for reporting animal research. PLoS Biol. 2010, 8, e1000412, doi: 10.1371/journal.pbio.1000412.
13.Klemm D., Kramer F., Moritz S., Lindstrom T., Ankerfors M., Gray D., Dorris A.: Nanocelluloses: a new family of nature-based materials. Angew. Chem. Int. Ed. Engl. 2011, 50, 5438-5466, doi: 10.1002/anie.2010001273.

14. Kołaczkowska M., Siondalski P., Kowalik M. M., Pęksa R., Dtuga A., Zają W., Dederko P., Kołodziejska I., Malinowska-Pańczyk E., Sinkiewicz I., Staroszczyk H., Śliwińska H., Stanisławska A., Szkodo M., Pałczyńska P., Jabłoński G., Borman A., Wilczek P.: Assessment of the usefulness of bacterial cellulose produced by Gluconacetobacter xylinus E25 as a new biological implant. Mat. Sci. Eng. C 2019, 97, 302-312, doi: 10.1016/j.msec.2018.12.016.

15. Mello L. R., Acantara B. B., Bermardes C. I., Boer V. H.: Late favorable results of duroplasty with biocellulose: clinical retrospective study of 20 cases. Arq. Bras. Neurocir. 2012, 31, 128-134.

16. Monreal G., Sherwood L. C., Sobieski M. A., Giridharan G. A., Slaughter M. S., Koenig $S$. C.: Large animal models for left ventricular assist device research and development. ASAIO J 2014, 60, 2-8. doi: 10.1097/MAT.0000000000000005.

17. Petersen N., Gatenholm P.: Bacterial cellulose-based materials and medical devices: current state and perspectives. Appl. Microbiol. Biotechnol. 2011, 91, 1277-1286, doi: 10.1007/s00253-011-3432-y.

18. Rajwade J. M., Paknikar K. M., Kumbhar J. V.: Applications of bacterial cellulose and its composites in biomedicine. Appl. Microbiol. Biotechnol. 2015, 99, 2491-2511, doi: 10.1007/s00253-015-6426-3.

19. Rashid S. T., Salacinski H. J., Hamilton G., Seifalian A. M.: The use of animal models in developing the discipline of cardiovascular tissue engineering: a review. Biomaterials 2004, 25, 1627-1637, doi: 10.1016/s0142-9612(03)00522-2.

Corresponding author: Maciej M. Kowalik, M.D., Ph.D., ul. Dębinki 7, 80-211 Gdańsk, Poland; e-mail: mkowalik@gumed.edu.pl 